Discussion Paper No. 768

\title{
ACCESS TO HEALTH INFRASTRUCTURE AND CHILD HEALTH DEVELOPMENT: EVIDENCE FROM POST-APARTHEID SOUTH AFRICA
}

\author{
Shinsuke Tanaka \\ The $12^{\text {th }}$ ISER-Moriguchi Prize (2009) \\ Awarded Paper
}

February 2010

The Institute of Social and Economic Research

Osaka University

6-1 Mihogaoka, Ibaraki, Osaka 567-0047, Japan 


\title{
Access to Health Infrastructure and Child Health Development: Evidence from Post-Apartheid South Africa*
}

\author{
Shinsuke Tanaka ${ }^{\dagger}$ \\ Boston University
}

January 2010

\begin{abstract}
A growing body of literature shows that child health has substantial long-term economic impacts. This study examines whether, and to what extent, increased access to health infrastructure leads to better child health status as measured by weight-forage z-scores. To assess the causal relationship, I exploit plausibly exogenous variation in access induced by the dramatic change in health policy in South Africa immediately after the end of apartheid. Using longitudinal household data, health services are found to improve the nutritional status of not only newly born babies but also children who were already born at low health status. Yet, the effects are significant only for boys.
\end{abstract}

JEL classification: I18, H54, J13, H51, O15

Keywords: child health, health infrastructure, South Africa

*I am extremely indebted to my advisors, Randall Ellis, Daniele Paserman, and Tavneet Suri, for extensive discussions and suggesions on this paper. I am also thankful to Alok Bhargava, Nicola Branson, Alfredo Burlando, Kenneth Chay, Susan Cleary, Taryn Dinkelman, Jane Fortson, Emily Gee, Gordon Hanson, Todd Idson, Marika Imagawa, Hirokazu Ishise, Takahiro Ito, Yukie Kamiya, David Lam, Kevin Lang, David Lee, Ken Leonard, Joshua Lustig, Di McIntyre, Omer Moav, Dilip Mookherjee, Keisuke Nakao, Tatsushi Oka, Emily Oster, Nancy Qian, Gail Thomas, Ingrid Woolard, Futoshi Yamauchi, Wesley Yin and seminar participants at Boston University, the Institute of Social and Economic Research (ISER) of Osaka University,the Southern Africa Labour and Development Research Unit (SALDRU) of the University of Cape Town, the 2009 North American Summer Meeting of Econometric Society, the 30th Nordic Health Economist's Study Group, the 24th Annual Congress of the European Economic Association, and the 2009 Northeastern Universities Development Consortium Conference for helpful comments and advice. Part of this research was carried out while the author was visiting the SALDRU. Financial support from the Graduate School of Arts and Sciences at Boston Univerity is gratefully acknowledged. The previous version of this paper was awarded the 12th Moriguchi Prize by the ISER at Osaka University. All errors are my own.

${ }^{\dagger}$ Department of Economics, Boston University. 270 Bay State Road, Boston, MA 02215. Email: stanaka@bu.edu. 


\section{Introduction}

A considerable amount of public resources have been spent in constructing health facilities and providing health services in low income countries, yet it remains unclear whether these investments lead to increased utilization in health services and improved health status among the poor. Two empirical difficulties complicate answering these questions. First, little is known about how poor households respond to the provision of public services. Second, many health services are provided in rich urban areas, and many of the social programs are targeted at certain groups of people. Hence, availability of health institutions or the intensity of access to health care services systematically varies across regions and often prevents researchers from credibly identifying the impacts of medical services.

In this paper I provide new evidence on the extent to which increased access to health services contributes to health status among poor children. To assess this, I exploit plausibly exogenous variations in access to medical care generated by a new reproductive health policy in South Africa. Historically, black Africans had severely limited access to health services under apartheid. The new democratic government, established in 1994, started providing free medical services to pregnant mothers and children under 6 years old. Two salient features under apartheid help address typical endogeneity problems that make it difficult to disentangle the effects of health services from the effects through other unobservable variables. First, the allocation of clinics was controlled by whites, over which black Africans had little control. Second, black Africans had low mobility from the regions in which they were forced to live during apartheid.

Using the KwaZulu-Natal Income Dynamics Study (KIDS), I merge longitudinal household surveys on health status during the early childhood with community information on infrastructure. I exploit two dimensions of variations in access across individuals. One variation comes from birth timing. Evidence supports that the new policy granted the poor with better access by relaxing budget constraints, which had been previously identified as the major barrier to undergoing medical treatment. Thus, comparing health status of chil- 
dren before and after the policy change provides an estimate of between-cohorts impact of substantial improvements in access. Another dimension is within-cohort variation that is determined by the community that a household resided in during the apartheid era. Households in communities with a clinic (hereafter the high treatment region) immediately gained access to health services as soon as the policy was initiated in 1994, whereas those who did not have a clinic in their communities (hereafter the low treatment region) continued to have poor access. ${ }^{1}$ With this exogenous variation, I compare health improvements between children living in the high and low treatment regions.

The results show that children who obtained access to health services achieved significant improvements in health status as measured by weight-for-age z-scores (WAZ). The point estimates suggest that the policy increased WAZ of newly born babies by 0.64 standard deviations and that of pre-primary school children by 0.57 standard deviations. This not only indicates that pre- and post-natal services are important determinants of health status but also suggests that health care during early childhood helps mitigate the low health status experienced at birth. However, the significant effects are found only for boys. This highlights a potential mechanism of unequal intrahousehold allocation of resources; boys are more likely to receive medical treatment than girls.

The effects would be spurious if there were intrinsic differences in household attributes leading to a differential health pattern in the absence of the policy change. This would be true if whites endogenously allocated clinics among black African's communities under the apartheid regime. In addition, the estimates would be biased if there were any unobservable changes that were concurrent with the policy reform and systematically varied between the two types of regions. This would be likely if post-apartheid investments were disproportionately made in the high treatment region. Thus, I conduct two placebo experiments to provide testable implications of each case. To test pre-treatment endogeneity, I investigate

\footnotetext{
${ }^{1}$ Throughout the paper, I use the term "community" to refer to a census enummerator subdistrict and "region" to refer to a group of communities that share the same characteristics, which is whether there was a clinic or not as of 1993.
} 
whether there is a systematic difference in health trends using only observations before the policy change. Further, making use of the fact that the policy affects only children under 6 years old, the basic idea to address post-treatment omitted variables is to investigate health improvements for older children who are aged 6 years old and above as of 1994. These cohorts provide appropriate counterfactual evidence during the post-apartheid era in the absence of the policy change because they are not entitled to receive free health services, but they must have still been affected by other changes in households or communities, if any. Both results indicate that the estimates are likely to be underestimated and to mark a lower bound of the overall impact of the policy.

By looking at the impacts of the dramatic change in health policy, the study contributes to knowledge in the realm of the effectiveness of health services and facilities in improving child health in low income countries. Many studies have shown strong correlations between the two as we often observe people with high income level in areas with better services and more qualified doctors (Jishnu Das and Jeffrey Hammer 2007). On the other hand, poor areas are more likely to have fewer health facilities, high absenteeism, and unhealthy people. As a consequence, there is ubiquitous phenomena of "wealthier is healthier" and "healthier is wealthier" in cross-sectional and some panel settings, but finding the causal relationship is not trivial (Lant Pritchett and Lawrence H. Summers 1996; Sarah L. Barber and Paul J. Gertler 2002; Anne Case, Darren Lubotsky, and Christina Paxson 2002; Abhijit Banerjee, Angus Deaton, and Esther Duflo 2004; Deaton 2006; Janet Currie and Wanchuan Lin 2007; Currie 2008). There are several reasons to expect that increased access may not necessarily improve health status. First, quality of health services in poor countries is often perceived to be low and inefficient. Simply expanding quantity of health facilities may not solve this problem. Second, the linkage between access and health status is theoretically and empirically ambiguous; Emily Oster (2009) presents a model with evidence that a mere increase in access may widen inequality and hurt disadvantaged group of people, particularly 
at a low level of access. ${ }^{2}$

It is of interest for many policy makers in developing countries to understand the extent to which providing access to medical care contributes to health improvement. There is added importance in exploring the topic because a growing body of literature has shown that health status, particularly early childhood nutrition, has substantial long-term economic impacts on later outcomes. It has been shown that children who experienced positive (negative) health shocks during early childhood perform better (worse) in school, earn higher (lower) income during young adulthood, and achieve higher (lower) health status and socioeconomics status up to the middle age (Harold Alderman, Jere R. Behrman, Victor Lavy, and Rekha Menon 2001; Paul Glewwe, Hanan G. Jacoby, and Elizabeth M. King 2001; Glewwe and King 2001; Case, Angela Fertig, and Paxson 2005; Alderman, John Hoddinott, and Bill Kinsey 2006; Almond 2006; Hoyt Bleakley 2007; Futoshi Yamauchi 2008; Taryn Dinkelman 2008; Sharon Maccini and Dean Yang 2009).

This paper also contributes to the contentious debate over the impact of price on take-up behavior among the poor. Many developing countries introduced or increased user fees to health services based on the argument that free provision of public services does not increase usage because even the poor do not value free or cheap public services and bypass them (Alaka Holla and Michael Kremer 2008; Klaus Deininger and Paul Mpuga 2004). Proponents also argue that imposition of user fees should sustain or improve quality of services. On the other hand, there is also evidence that imposing user fees on the poor had significantly negative impacts on their usages (Asenso-Okyere et al. 1998; see further discussions in Deininger and Mpuga 2004). The new reproductive health policy that I focus on removed user fees from health services, providing a rare environment to observe behavioral responses to free medical care. $^{3}$

\footnotetext{
${ }^{2}$ The relationship appears to be relatively monotonic in developed countries. Studies have found that increased access contributed to a sharp reduction in the relative infant mortality of blacks in the United States (Kenneth Chay and Michael Greenstone 2000; Douglas Almond, Chay, and Greenstone 2007).

${ }^{3}$ Another example of free health services is Deininger and Mpuga (2004), where they focus on the abolition of health user fees in public hospitals in 2001 in Uganda. This study differs from their study in a key aspect that the policy in South Africa exhibits a discontinuous entitlement at age 6, which enables me to address
} 
The rest of the paper is structured as follows. Section 2 introduces the new health policy in the historical context, and Section 3 describes the data and the summary statistics. Section 4 presents the empirical strategy, and Section 5 discusses the results. Section 6 tests the validity of the identification assumptions, and Section 7 concludes.

\section{Reproductive Health Policy in South Africa}

The South Africa's apartheid policy has shaped it as one of the most discriminatory countries in the world. Society was characterized by racial and spatial disparities and disintegration. Geographical segregation driven by the Bantu Authorities Act of 1951 forced black Africans to move into underdeveloped and infertile areas, called "homelands," where few infrastructures existed. Racial discrimination was intensified by the Bantu Homelands Citizenship Act of 1970, which deprived South African citizenship from black Africans in homelands.

The legacy of apartheid ideology also formulated political, social, and economic institutions. For example, government institutions were built for each race defined as white, colored, Indians/Asians, and Africans. Most of the resources were controlled by the white minority in urban areas without any representatives from the black majority (Diane Cooper et al. 2004). Among these geographical and racial inequalities in resources and services allocations, the health sector in black communities was also short of facilities and finances. The absence of comprehensive health policies prior to 1994 led to a significant lack of coordination and integration in providing health services, symbolized by as many as eighteen Departments of Health at the central and regional government levels. ${ }^{4}$ Black Africans constitute the most disadvantaged and underserved group; their access to health services was constrained by a lack of facilities, doctors, and medicines at public health institutions as well

unobservable time effects. Because Uganda policy provided universal free services, their study interprets the time effect as the impact of the policy change.

${ }^{4}$ Specifically, these include the Department of National Health and Population Development, three "own affairs" Department of Health for white, colored, and Indian people, 10 health departments for African people in each "homelands," and the departments for four provinces (Klugman and McIntyre 2000). 
as by the financial burden on transportation to health facilities and out-of-pocket payments for health services (Department of Health 2000).

Under the pressure from the international community, a series of negotiations to dismantle apartheid took place starting in 1990. In April 1994, apartheid was formally abolished, and a new democratic government was established under the leadership of President Nelson Mandela. In an effort to eliminate substantial racial and geographic inequalities, various new policies were passed to ensure improved access to health care with priority for previously disadvantaged black mothers, women, and children (Department of Health 1995). Most notably, the Reconstruction and Development Programme (RDP), along with National Health Plan for South Africa (African National Congress 1994), proclaimed free health care services to pregnant mothers and children under 6 years old in the public sector (Republic of South Africa 1994). Free services to mothers included pre- and post-natal care from confirmation of pregnancy until 42 days after delivery. The policy was implemented in June 1994.

The free health care provision granted a significant increase in access to health services to black African, who previously identified cost of medical services as the major barrier for seeking treatment. Community Agency for Social Enquiry (CASE) (1995), a national representative survey of households before the policy change, notes that "not affordable" was the most common reason for foregoing health care (73.8 percent) among black families, followed by lack of transportation modes (11.5 percent). This contrasts to the fact that only 23.2 percent of whites listed the cost of medical care as the primary constraint. In addition, 90 percent of black Africans did not have health insurance, whereas 76 percent of whites did (CASE, 1995). Various studies have found that removing user fees extended antenatal care delivery to women who were not previously reached and increased the number of patients under 6 years old (Robert Cameron 1996; David McCoy 1996; Department of Health 1998; Helen Schneider and Lucy Gilson 1999; David Wilkinson et al. 2001; Cooper et al. 2004). 


\section{Data Source and Descriptive Statistics}

The analysis in this paper is based on the data from KIDS, a longitudinal household survey in the KwaZulu-Natal province of South Africa. ${ }^{5}$ The first wave of 1993 (hereafter KIDS93) is part of the 1993 Project for Statistics on Living Standards and Development (PSLSD), the first comprehensive household survey in South Africa. To address dramatic changes in South African society since 1994, African and Indian households of the PSLSD sample in the KwaZulu-Natal province were revisited in 1998 (hereafter KIDS98). As the largest province in South Africa, KwaZulu-Natal is home for approximately 9.4 million of total 40 million national population and is characterized by high rates of poverty and deprivation from basic needs. Though it is not the poorest province in South Africa, it certainly shares many characteristics with other former homelands (Stephan Klasen 1997; Murray Leibbrandt and Ingrid Woolard 1999; May et al. 2000). The original sample contains 1,389 households (215 are Indian and 1,174 are Africans), of which 1,178 households (85 percent) were followed up in 1998, which involves limited concern about attrition (Michael R. Carter and John A. Maluccio 2003).

There are several advantages to using KIDS. First, it contains household level of information on demographics and socioeconomic status. In addition, anthropometric data are provided for all children aged 6 years old and below in KIDS93 and for all children aged 11 years old and below in KIDS98. The community survey provides information of available health institutions in each community. Second, the timing of data collection is suitable; comparison of the two waves captures changes in child health status from right before to after the policy change.

For the analysis of the present study, the samples are restricted to black Africans. This is appropriate because black Africans not only constitute the majority of the South African

\footnotetext{
${ }^{5}$ The surveys were jointly conducted by the University of KwaZulu-Natal (UKZN), the University of Wisconsin-Madison, and the International Food Policy Research Institute (IFPRI), the London School of Hygiene \& Tropical Medicine, and the Norwegian Institute of Urban and Regional Studies.

A more detailed description of KIDS is provided in Julian May et al. (2000) and May et al. (2007).
} 
population but also account for most of the poor. Because the new government aimed at protecting and equalizing opportunities for the most disadvantaged group, black Africans are most likely to have benefited from the new health policy.

The primary goal of the study is to assess the effects of gaining access to health care on health status. Health status is measured using the anthropometric indicators, from which WAZ is calculated. ${ }^{6,7}$ To address impacts of increasing access to health care services on children, I link their health status with the infrastructure information from the community survey. In this paper, I focus on clinics as the primary health care facility to provide health services to pregnant mothers and children. Anecdotal evidence supports this approach since most black Africans refer to public clinics for the child's first treatment or for antenatal care. $^{8}$

Table 1 presents baseline summary statistics on the individual level of health status and a variety of household and community characteristics in 1993 by region. Each community in 1993 had either zero or one clinic. I refer to the communities with a clinic as high treatment region. The exposure is high in a sense that households gained immediate access to health

\footnotetext{
${ }^{6}$ Detailed descriptions of how to construct WAZ and how reference groups were sampled are discussed in WHO Multicentre Growth Reference Study Group (2006). Simply summarizing, the WAZ of child $i$ are calculated as:

$$
\mathrm{WAZ}=\frac{W_{i}-W_{g}}{S D_{g}}
$$

where $W_{g}$ is the median weight of the reference group in the world population, and $S D_{g}$ is the standard deviation of the reference group.

${ }^{7}$ Many other studies also use height-for-age z-scores (HAZ) to measure health status. It is widely recognized in the literature that WAZ characterizes short-run fluctuations in nutritional status, while HAZ captures long-term accumulation of nutritional history. The main reason why I focus on WAZ in this paper is that most of the samples in the analysis are too young, such as ages less than three years old, and height does not differ much among these children. Gustavo J. Bobonis, Edward Miguel, and Charu Puri-Sharma (2006) provide support on this. They find the effects of iron supplementation and deworming drugs on WAZ among preschool children, yet no effect is observed on HAZ.

Another concern with height is that it is subjected to large measurement error particularly for infants who are not able to stand up yet, whereas weight can be measured relatively more accurately. Glewwe, Jacoby, and King (2001) find that about 52 percent of the total variance in HAZ, even for children at the school enrollment, is caused by measurement error.

I used HAZ, nonetheless, and found no significant effect. Because HAZ is a dependent variable in my analysis, the measurement error leads to larger standard error.

${ }^{8}$ Evidence shows that Africans visit public clinics for antenatal services (69 percent) and for the first treatment (40 percent), whereas whites seek private doctors for antenatal care (79 percent) and for the first treatment (74 percent) (CASE 1995). See also, Pranitha Maharaj and John Cleland (2005)
} 
services as soon as the policy was initiated. On the other hand, families in the communities without a clinic, referred as the low treatment region, needed to wait until facilities became ready or travel for a long distance to receive treatment.

[Table 1 about here]

It shows that twenty-six communities belong to the high treatment region, while twentyeight communities are in the low treatment region. The third column presents the differences in means between the regions. It shows that none of the individual and household characteristics is significantly different between the two regions. This suggests that black families had limited ability to determine the extent of infrastructure in their communities, bolstering the view that the allocation of clinics among black communities was orthogonal to family attributes. There is some evidence that communities in the high treatment region are more likely to have other types of social facilities. Consequently, cross-sectional estimates of the relationship between health facilities and health status may confound unobservable differences in communities and may involve severe omitted variable bias. The next section discusses this paper's challenge to develop an appropriate counterfactual for health status among children in the absence of access to health institutions.

\section{Empirical Strategy}

The empirical framework is established to compare children's health growth between the two regions before and after the policy change. The new reproductive policy in 1994 provides exogenous variations in access to health infrastructure, which helps avert potential endogeneity between underlying family background and availability of services. Consequently, the treatment is determined by the two dimensions of variation in exposure to the new health policy. First variation comes from birth timing. Because free health service started in 1994, any 
children observed in KIDS93 are not exposed to the policy. On the other hand, all children born after 1994 in KIDS98 are eligible for free health services. Second variation across individuals within the same cohort is determined by the residential community: whether the household lived in the high or low treatment region as of 1993. This leads to the baseline regression:

$$
W_{i h c l}=\beta_{0}+\beta_{1}\left(H_{i g h} * Y \text { oung }_{l}\right)+\beta_{2} H i g h_{c}+\beta_{3} Y \text { oung }_{l}+\mathbf{X}_{h}^{\prime} \boldsymbol{\beta}_{4}+\left(\mathbf{X}_{c}^{\prime} * Y \text { oung }_{l}\right) \boldsymbol{\beta}_{5}+\varepsilon_{\text {ihcl }}
$$

where $W_{i h c l}$ is the weight-for-age z-score of individual $i$, in household $h$, in residential community $c$, in cohort $l$. Young $=1$ if cohort $l$ is affected by the policy (post-treatment cohorts, hereafter referred as young cohort), while $Y$ oung $_{l}=0$ for pre-treatment cohorts, hereafter referred as old cohort. High $=1$ if community $c$ had a clinic in 1993 (often known as treatment group), and is otherwise equal to 0 (control group). ${ }^{9} \mathbf{X}_{h}$ is an additional vector of household characteristics, $\mathbf{X}_{c}$ contains a vector of community characteristics, and $\varepsilon_{i h c l}$ is an unobserved individual disturbance. $\mathbf{X}_{c}$ is interacted with a young cohort dummy because it takes into account other types of health facilities and programs that may be correlated with the existence of clinics and may potentially confound effects on health outcomes in 1998. For example, if other governmental programs, such as immunization campaigns provided through clinics, were the key determinants of health improvement, the results would be misleading unless they are explicitly controlled. ${ }^{10}$ The parameter of interest is $\beta_{1}$, which represents the difference-in-differences effect of a clinic on an outcome variable.

To further refine variations across cohorts and communities, the main strategy employed is:

$$
W_{i h c l}=\delta_{0}+\delta_{1}\left(H_{i g h} * Y \text { oung }_{l}\right)+\mathbf{X}_{h}^{\prime} \boldsymbol{\delta}_{2}+\left(\mathbf{X}_{c}^{\prime} * Y o u n g_{l}\right) \boldsymbol{\delta}_{3}+\eta_{c}+\psi_{l}+e_{i h c l}
$$

\footnotetext{
${ }^{9}$ A similar specification is used in Duflo (2001), which examines the causal effects of school construction on educational attainment and income level in Indonesia.

${ }^{10}$ Although it is important to control for these community characteristics, the key assumption that black families did not have influence over the availability of clinics suggests that $\beta_{1}$ can be estimated even without controlling for these attributes. However, the inclusion of them still enhances the precision of the estimates with lower standard error. Nonetheless, the results are presented with and without control variables. This helps test the validity to the identification assumption.
} 
where $\eta_{c}$ is fixed effects of a residential community that the household resided in 1993, and $\psi_{l}$ is cohort fixed effects. All standard errors are clustered at $c \times k$ level, where $k \in\{$ Y oung, Old $\} .{ }^{11}$ The coefficient of interest, $\delta_{1}$, is expected to be positive if a clinic delivers beneficial health services to children, or equivalently if gaining access to health care leads to improved health status. The effect can be interpreted as causal based on the identification assumption that, after controlling for the birth timing and residential location, the intensity of the change in access to health infrastructure is exogenously determined by the policy change. The potential threat is to confound any cohort-specific and community-level unobservable variables that are correlated with the availability of clinics and have direct impacts on an outcome.

This raises several potential concerns that this identification assumption may be violated. First issue is pre-treatment bias. For example, if the initial allocation of clinics under apartheid was endogenously determined by whites, targeting to build facilities in communities where people are somehow better (worse) at responding to health growth, then simple comparison of outcomes between treated and non-treated regions would be upwardly (downwardly) biased. This should be characterized by differential pre-trends of health development between the regions.

Second concern is omitted variables that correlate with the initial allocation of clinics. For instance, Table 1 shows that communities with a clinic as of 1993 were more likely to have various other types of infrastructure. In addition, if these communities are politically important and are likely to receive further investments or projects after 1994, then the estimates mistakenly pick up these effects. I take two approaches of placebo experiments in pre- and post-treatment period to address testable implications of the validity of the identification strategy, as discussed in Section 6. Evidence shows that confounding variables,

\footnotetext{
${ }^{11}$ This means that any correlations between households within the same community during the same period are allowed, but it assumes no correlation between households within the same community over time. This accomodates the fact that South Africa experienced drastic changes in various facets of society before and after 1994. Nonetheless, standard errors are also clustered at community level, allowing for correlations across time, but the results did not significantly change.
} 
if any, tend to understate the estimates.

\section{Empirical Results}

\subsection{Age Level Analysis}

The first primary question posed in this study is whether gaining access to health infrastructures, such as clinics, improves health status among children. Figure 1 presents the average health status of children across ages. Panel A exhibits somewhat parallel trend between the two regions in KIDS93. This provides graphical support that, prior to the policy change, children in both regions share a similar pattern of health development. Panel B, which uses observations in KIDS98, tells different episodes. Children aged right to the dashed line comprise non-exposed cohorts because they are more than 6 years old upon the policy start. A sharp increase in WAZ is depicted in the high treatment region when the cohorts begin to be affected by the new health policy.

[Figure 1 about here]

Panel A of Table 2 illustrates the identification strategy, laid out by the equation 1 , using a simple two-by-two matrix. It compares means of health status between the same age groups across the two types of regions. I consider children aged 0 to 3 in KIDS93 as the old cohort. This provides baseline health status among non-exposed cohorts, as they are observed prior to the policy change. I then refer to children aged 0 to 3 in KIDS98 as the young cohort. They can be considered as treated cohorts since they have full exposure to the new policy since birth. ${ }^{12}$ While the average health status increases in both regions, it increases significantly more in the high treatment region. It is also worth noting that the

\footnotetext{
${ }^{12}$ I omit 4-year-old children from the fully exposed group because the exposure to the policy starts when babies are still in utero to account for ante-natal services.
} 
average health status in 1993is lower in the high-treatment region, though the difference is not statistically significant. This evidence reassures that children in the high-treatment region did not benefit from clinics prior to 1994 possibly due to barriers to access that prevented them from receiving health care.

[Table 2 about here]

Table 3 presents estimates from a series of regression analyses, whose sample corresponds to Panel A of Table 2. Column (1) reproduces the results from Table 2 as the benchmark specification. Column (2) provides baseline results of equation 2, introducing community and cohort fixed effects. Column (3) and (4) control for various household or community characteristics. Of other variables in household characteristics, the logarithm of monthly income, which is a proxy of household wealth, is strongly associated with the health status of children. This can be interpreted in terms of the resource constraint; cost of health care was the major constraint for undergoing services. Both of the community characteristics are highly correlated with child health status. The estimate of interest becomes even larger with the inclusion of community characteristics, indicating that the health effect through clinical services are not overstated by other governmental health programs or health facilities. Although these variables are markedly important in themselves, their inclusion does not alter the difference-in-differences estimates. This is suggestive that the availability of clinics in 1993 is not related to any of these background characteristics. Column (5) provides the preferred estimate, indicating that, after controlling for all variables, gaining access to health services improved the health status of newly born babies by 0.64 standard deviation away in terms of WAZ. This highlights particularly the importance of ante- and post-natal services.

[Table 3 about here]

I now consider differential effects by gender; it is commonly observed in developing countries that most beneficial effects are enjoyed only among boys but not among girls. This is 
often explained by an unequal intrahousehold allocation of resources, as is often prevalent in Asian countries in the context of consumption behaviors. To assess this, I divide the sample by gender.

[Table 4 about here]

Panel A of Table 4 reveals that positive effects found in Table 3 are driven mostly by boys; the point estimates are even larger and are highly significant. On the other hand, the effects are consistently positive for girls yet never statistically different from zero. This highlights a potential mechanism of unequal intrahousehold allocation of resources; boys are more likely to receive medical treatments. Figure A1, which presents similar pre-trends in health status between boys and girls, provides graphical support that the results are not driven by intrinsic biological differences by gender. Further, Table A2, which shows the results based on the regressions allowing for differential impacts across ages, ${ }^{13}$ uncovers a result that positive health improvement is observed for girls aged 0. Consistent with previous findings, none of the other cohorts among girls experienced improved health status. This provides further support of an unequal allocation of resources for girls; all children, regardless of their sex, benefit from gaining access to prenatal services, during which a child's gender is unknown, yet girls fall behind in later years.

\subsection{Cohort Level Analysis}

This subsection aims to answer a different aspect of the question: whether gaining access to health care improves health status of children even after they undergo low health status at

${ }^{13}$ The regression is based on interacting the region dummy by each cohort dummy;

$$
Y_{i h r k}=\alpha_{0}+\alpha_{i l} \sum_{l}\left(H_{i g h} \times \lambda_{i l}\right)+\mathbf{X}_{h}^{\prime} \boldsymbol{\alpha}_{1}+\left(\mathbf{X}_{r}^{\prime} * Y o u n g_{k}\right) \boldsymbol{\alpha}_{2}+\eta_{r}+\psi_{l}+\epsilon_{i h r k}
$$

where $\lambda_{i l}=1$ if individual $i$ is age $l$ in 1998. Each coefficient $\alpha_{1 l}$ can be interpreted as an effect on a given cohort with respect to the reference cohorts. 
birth. To mitigate different cohort-specific variation, this can be addressed by tracking the same cohorts. A longitudinal setting of the dataset allows me to trace the same individuals over time. ${ }^{14}$ Panel B of Table 2 provides means of health status among each cohort by region, and regression estimates are presented in Table 5. In both tables, children aged 0 to 3 in KIDS93 are referred as the old cohort, and children aged 5 to 8 in KIDS98 as the young cohort. ${ }^{15}$ The advantage of this comparison as opposed to the age level analysis is that these cohorts were already born when the policy started. Thus, it helps identify whether gaining access to post-natal services or health services during early childhood also brings about health improvement.

Results in Table 5 are in line with the age level analysis; the difference-in-differences estimates are robust to the inclusion of various household and community characteristics, and household income illustrates an important avenue of resource effects. One interesting disparity is that the household size is now negatively associated with health status.

[Table 5 about here]

Note that these cohorts experienced significantly low health status in early childhood; Panel B of Table 2 shows that the average WAZ is -0.414 in the low treatment region and even lower at -0.545 in the high treatment region. The results provide added significance to gaining access to clinics; it not only helps newly born infants through ante-natal services but also partially offsets the poor health status experienced at birth. Panel B of Table 4 illustrates differential effects of policy by gender. Again, positive and significant effects are found only for boys, and no statistically significant effects are found for girls.

\footnotetext{
${ }^{14}$ Panel B of Table 4 show slighly different numbers of observations in each cell. This should indicate that I do not refer to exactly the same individuals but instead follow the cohorts by age. Different timings of birthday and survey collection generate slightly different ages even within the same cohorts, but because these timings are exogenously determined, the bias should be negligible.

${ }^{15}$ Although, as mentioned, they are the same cohort, I still use the term "young" and "old" cohort to be consistent throughout the paper. They are simply the same cohort at "younger" and "older" times.
} 


\section{Threats to Validity}

\subsection{Endogenous Allocation of Health Facilities in Pre-treatment Period}

The key to the identification strategy is that initial allocation of clinics is exogenously determined and does not confound variables that are correlated with health outcomes. There are two important sources of selection bias. The obvious, and foremost, important concern is whether it is plausible to believe that black African families had limited control over availability of health institutions in their communities. South Africa under apartheid was characterized by extreme domination by the white minority over the black majority; most of the resources were allocated for white communities, and little was distributed to black communities. For example, Case and Deaton (1999) describe that school quality, measured by pupil-teacher ratios, was extensively dispersed across black districts immediately before the end of apartheid. Using evidence that socioeconomic characteristics among black families are not associated with school resources, OLS regressions of various school outcomes on school quality can estimate the class size effects. Following their work, ${ }^{16}$ I test whether the observable characteristics of black households are associated with the availability of health facilities. If black families could exert extensive power to allocate health facilities in their neighbors, there should be a significant correlation between the two. Table 6 explores this balancing test. It shows that no household attributes is the significant determinant of initial allocation of health facilities in the pre-treatment period. This is reassuring that there is no selection bias from household's side; black families could not influence the intensity of infrastructure in their communities.

[Table 6 about here]

\footnotetext{
${ }^{16}$ Case and Deaton (1999) use data from PSLSD in 1993. As mentioned, KIDS93 focuses on observations in KwaZulu-Natal from PSLSD.
} 
Yet, this does not directly rule out the concern that there are unobservable rules that determined the allocation of health facilities- this is the second source of selection mechanism. ${ }^{17}$ I have exchanged excessive discussions with local economists and doctors, but it still remains unclear how the allocation was determined in the first place. However, even if there was some systematic rule on how to build clinics among black communities, this would invalidate the identification strategy only if, in the absence of the policy change, it led to differential trends in health growth between the two regions. In other words, the empirical strategy is still valid if the pattern of health growth among children is not systematically different across regions. This is violated if households with access to clinics in 1993 had a higher rate of health accumulation by taking an advantage of initial access to health services. The first placebo experiment is designed to test whether children exhibit the same trend across ages during the pre-treatment period.

As previously shown, Panel A of Figure 1 depicts such trends in KIDS93; it illustrates that health development across ages appears to follow the same trend between the two regions. Panel C of Table 2 presents testable implications of this placebo experiment. Note that the most appropriate comparison of cohorts may be the one between the same age groups both before the policy change. ${ }^{18}$ However, because the survey was conducted only once prior to 1994, I compare the closest cohorts examined in Panel A. I refer to cohorts aged 0 to 3 in KIDS93 as the young cohort and to cohorts aged 4 to 7 in KIDS93 as the old cohort. Such comparison serves as an appropriate falsification test because both age groups have no exposure to the policy. The difference-in-differences estimate do not show any significant positive trends in the high treatment region. Panel $\mathrm{C}$ of Table 7 provides regression results of this comparison. The evidence supports that children in the high-treatment region do

\footnotetext{
${ }^{17}$ Case and Deaton (1999) also raise the similar concern and have discussed with South African academics, the then Ministry of Education, and the Department of Education and Training on the allocation rule of teachers across schools. Their conclusion is that, although there were some guildelines, observations from data do not support them, and most of the allocations appear to be determined by bureaucratic minds and did not meet regional needs. See further discussions in their paper.

${ }^{18}$ For example, the ideal comparison is between children aged 0-3 in the 1993 dataset and chidren aged 0-3 in the 1990 dataset, if data would have been collected in 1990.
} 
not have higher rates of health improvement; if they did, the estimates would show spurious positive correlations. The negative estimates, though insignificant, indicate that confounding variables in pre-treatment period, if anything, would underestimate the benefits generated by the policy change. The results are suggestive that availability of clinics in 1993 brought about limited access or benefits to children in the pre-treatment period, and the effects are not driven by the inappropriate identification assumptions.

[Table 7 about here]

\subsection{Omitted Variable Bias in Post-treatment Period}

One of the difficulties associated with evaluating social policies is that there may be several other changes happening concurrently, and it is difficult to disentangle these effects. The new health policy in South Africa is not exceptional; there may be unobservable changes in policies or infrastructure in post-apartheid era specific in the areas with clinics. This is likely if new investments are made based on the initial existence of clinics. This subsection

discusses several issues in post-treatment period, which potentially lead to omitted variable bias in the treatment effects.

First concern is the construction of new clinics between 1994 and 1998. The policy emphasized previously deprived and underserved areas to meet the goal of racial and geographical equality. Table 8 presents evidence to support this aim that by 1998, a significantly larger number of clinics were built in communities without a clinic as of 1993.

[Table 8 about here]

However, I refer to areas with a clinic in 1993 as the high treatment region for several reasons. The average change in the number of clinics per community between KIDS93 and 
KIDS98 is 0.65 (with the standard deviation of 0.95 ), yet the data contain no information on exactly when each clinic was built or started provision of services. This makes it difficult to know how many clinics were available when each cohort was born. Rather, the government reported that Clinic Upgrading and Building Programme, initiated as a Presidential Lead Project in 1994, did not bring about noteworthy outcomes at the early stage. ${ }^{19}$ Further evidence shows that construction of clinics was substantially slow in the KwaZuluNatal province due to political instability and violence (Cameron 1996; Sultan Khan, Benoit Lootvoet, and Shahid Vawda 2006); even the first democratic election did not take place until 1996. These pieces of evidence are consistent with the assumption that clinics observed in 1998 are more likely to have been built in later years, namely close to 1998, and thus it validates the assumption that areas with a clinic in 1993 granted immediate and higher exposure to the policy. It is also worth noting that even if clinics were built at earlier stages, the results mark the lower bound of the estimates.

Second concern is that the treatment variable simply proxies new investments conditional on availability of clinics, such as quality change in health facilities (i.e. range of medical services, availability of drugs or equipment, workload of physicians, number of beds, or interactions between doctors and patients). If so, this would lead to a different policy implication; the government should allocate more resources to improving the quality of services at existing facilities, rather than to expanding the physical availability of health institutions. Another possibility is that communities initially with a clinic are politically important and thus are more likely to receive further infrastructure or projects, if not clinics. Then, the positive effects presented so far may be actually picking up these effects, acting as a reduced-form analysis of the new investments. The second placebo experiment investigates such potential bias during the post-treatment period. The basic framework of such falsification test is that If any other changes have a first-order effect, I should observe

\footnotetext{
${ }^{19}$ Advancement was made after August 1995, when a Fast Track Clinic Building Process was initiated to accelerate constructing and upgrading clinics, particularly in rural areas. By March 1998, approximately R710m had been spent (Department of Health 1995).
} 
improvements in health status even among people who are not directly affected by the new health policy. This can be tested by comparing cohorts aged 5 to 7 in KIDS93 and cohorts aged 10 to 12 in KIDS98. Because these children are 6 years old and above as of 1994, they have no exposure to the health policy through $1998 .{ }^{20}$ However, even these cohorts should be affected by new investments in any other sorts. If these changes were to confound health effects, the coefficient of the difference-in-differences estimate should be positive. As shown in Panel D of Table 2 as well as in regression results in Panel D of Table 7, this is not the case. The coefficients are negative and marginally insignificant, indicating that children in the low treatment region improved health slightly more. The results are rather consistent with the fact that post-apartheid policies were disproportionately targeted into deprived areas. In terms of the quality change in health services, the results reflect anecdotal evidence that quality improvement was an even more difficult task than constructing new clinics in the South African labor market context. Constrained by the existing labor agreements, transferring staff from one place or facility to another was restricted (Lucy Gilson et al. 1999). The working conditions worsened partly because the new health policy did not ameliorate staffing costs, which remained to account for a large amount of health expenditure (McCoy 1996). As a result, it led to staff shortages, and overburdened existing personnel, which further contributed to lowering staff morale and to raising barriers to providing high-quality services. Furthermore, the overcrowding of patients and the lack of drugs were left unsolved. Various studies show that patients perceived the quality of services deteriorated since 1994 (McCoy 1996; Sharon Fonn et al. 1998; CASE 1999; Gilson et al. 1999; Di McIntyre and Barbara Klugman 2003; Gilson and McIntyre 2007).

In summary, unobservable changes in other aspects of society do not appear to be confounding factors. Instead, removing fees, particular to young children, had immediate effects on lowering barriers in access to health care and contributed to health development. This

\footnotetext{
${ }^{20}$ Actually, a new policy was passed in 1997, and it eliminated all user fees at primary care in the public sector. This means that even these cohorts, who were certainly not affected by the new reproductive health policy in 1994, were affected and gained access to health services. Yet, I simply do not account for this policy since it does not alter my assumptions or results.
} 
does not rule out the importance of quality improvement. Rather, this simply indicates that the environment in South Africa helps separate the pure effect of access from quality change, and interactions between quantity and quality should certainly promote further health development. The trade-off between these two should be an interesting topic for future research.

\subsection{Identifying the Mechanism: Access versus Alternative Hy- potheses}

The effects, presented so far, suggest that gaining access to health care, by removing the financial burden, is a driving factor of health improvement. As robustness check of the causal mechanism, this subsection considers alternative channels for the results.

\subsubsection{The Migration to Regions near Clinics}

The presumption that black families had limited impacts over the initial allocation of health facilities does not rule out the possibility that they could still migrate to regions nearby clinics. Yet, this is not a case for blacks prior to the fall of apartheid. As described, under apartheid, millions of black Africans were forced into homelands. They had little freedom to choose a place to live, and their mobility was severely restricted, making it difficult to migrate to areas with better health infrastructure. However, the demise of apartheid also freed black Africans to migrate out, which leads to a change in composition of sample population in the high and low treatment regions. To avoid this geographical self-selection bias after 1994, I use communities that households lived in 1993 as their residential location, instead of current communities. Both are highly correlated, as approximately 95.3 percent of the sample households still live in the same community as in 1993, yet the former is predetermined and not endogenous to selection into the high treatment region. Nonetheless, I repeat the main analysis using only the samples who did not migrate by 1998, shown in 
Table A1. The main results do not alter, suggesting that migration itself cannot explain the main results.

\subsubsection{Health Services versus Health Education}

Another issue is that the effect of gaining access to clinics is not due to health services but due to health education provided at clinics. It is widely observed in developing countries that parents lack basic knowledge or information on sanitation and child health. ${ }^{21}$ For example, CASE (1995) shows that 23 percent of black African households use unpiped water, such as from a river, stream, or dam, and 89 percent of them drink it without boiling it. To spread basic health information to the public, clinics and other public health facilities served as important bases of educational campaign. While it is difficult to isolate effects through such channel, aforementioned two pieces of evidence support the argument that health education does not appear to be a key factor. One is that, as shown in Table 4, positive health improvements are observed only for boys. If health education mattered more, this would be conceivably implausible because implementing sanitary behaviors is mostly costless, e.g., boiling water or washing hands, and thus it involves no need to exclude girls. Furthermore, as Panel D of Table 7 presents, there was no effect on non-exposed cohorts. Even if there existed gender bias in sanitary controls, this placebo experiment would show positive effects if health education were a key determinant. Therefore, health education cannot simply explain the positive association between availability of clinics and health improvements.

\subsubsection{Fertility}

A further concern is that the free antenatal services might have altered black African women's fertility behaviors. The change could be either positive or negative. It could be positive if women take advantage of the policy and become pregnant more frequently. It could be

\footnotetext{
${ }^{21}$ It is well-known that PROGRESSA in Mexico required parents to receive health education in order to obtain a cash transfer.
} 
negative if women take into account a decrease in infant mortality through antenatal care and lower the number of births. The reason why this mechanism could potentially bias the results is that it shifts the distribution of health status among newly born babies; with increased fertility, the estimates provide lower bounds since less healthy babies, who had not been born alive previously, were born alive now. Or, with decreased fertility, the estimates are upwardly biased, erroneously picking up effects of expanded intrahousehold allocation of resources to each child. Nonetheless, extensive studies show that there has not been any changes in fertility (McCoy 1996; Schneider and Gilson 1999; Tom A. Moultrie and Ian M. Timaeus 2003), suggesting that fertility is unlikely to generate bias in the analyses.

\section{Conclusion}

This paper exploits exogenous variation in access to health infrastructure brought by the new reproductive health policy in the post-apartheid period in South Africa. This quasiexperimental design provides a rare opportunity to address the effects of gaining access to medical services on health status among children. The analysis employs a difference-indifferences approach to examine how the health status of children who obtained access to health services improves.

The results suggest that free health services have improved the health status of not only newly born babies but also of children who were already born when the policy was initiated. Such positive effects are observed only for boys but not for girls. The results highlight an unequal intrahousehold allocation of resources that favors boys. Further evidence helps identify that access to health services is the key mechanism through which child health status has been improved.

These results present several important policy implications for South Africa and other less developed countries. First, freeing user fees is effective in increasing access in an environment where poor households face significant budget constraint. Second, benefits of increasing 
access are substantial during early childhood even when some quality deterioration of the services are evident. While this promotes further expansion in investing the quantity of fiscal infrastructure, the combination of quantity and quality betterments should boost child health status. Third, merely increasing access to health services does not solve gender inequality. The pattern of this finding is consistent with Oster (2009), who argues that a simple increase in overall level of access to social programs is not sufficient; it may not benefit women but even lead to greater gender inequality. Understanding the precise mechanism of gender bias in medical resources and how interventions should be made to benefit girls is an important topic for future research. 


\section{References}

[1] African National Congress. 1994. A National Health Plan for South Africa. Paper prepared by the ANC with the technical support of WHO and UNICEF, Johannesburg.

[2] Alderman, Harold, Jere R. Behrman, Victor Lavy, and Rekha Menon. 2001. "Child Health and School Enrollment: A Longitudinal Analysis." Journal of Human Resources, 36(1): 185-205.

[3] Alderman, Harold, John Hoddinott, and Bill Kinsey. 2006. "Long Term Consequences of Early Childhood Malnutrition." Oxford Economic Papers, 58: 450-474.

[4] Almond, Douglas. 2006. "Is the 1918 Influenza Pandemic Over? Long-term Effects of In Utero Influenza Exposure in the Post-1940 U.S. Population." Journal of Political Economy, 114(4): 672-712.

[5] Almond, Douglas, Kenneth Y. Chay, and Michael Greenstone. 2007. "Civil Rights, the War on Poverty, and Black-White Convergence in Infant Mortality in the Rural South and Mississippi." Unpublished.

[6] Asenso-Okyere, W. K., Adote Anum, Isaac Osei-Akoto, and Augustina Adukonu. 1998.

"Cost Recovery in Ghana: Are There Any Changes in Health Care Seeking Behaviour?" Health Policy and Planning, 13(2): 181-188.

[7] Banerjee, Abhijit, Angus Deaton, Esther Duflo. 2004. "Wealth, Health, and Health Services in Rural Rajasthan." American Economic Review Papers and Proceedings, 94(2): 326-330.

[8] Barber, Sarah L., and Paul J. Gertler. 2002. "Child Health and the Quality of Medical Care." Unpublished.

[9] Bleakley, Hoyt. 2007. "Disease and Development: Evidence from Hookworm Eradication in the American South." Quarterly Journal of Economics, 122(1): 73-117. 
[10] Bobonis, Gustavo J., Edward Miguel, and Charu Puri-Sharma. 2006. "Anemia and School Participation." Journal of Human Resources, 41(4): 692-721.

[11] Cameron, Robert. 1996. "The Reconstruction and Development Programme." Journal of Theoretical Politics, 8(2), 283-294.

[12] Carter, Michael R., and John A. Maluccio. 2003. "Social Capital and Coping with Economic Shocks: An Analysis of Stunting of South African Children." World Development, 31(7): 1147-1163.

[13] Case, Anne, and Angus Deaton. 1999. "School Inputs and Educational Outcomes in South Africa." Quarterly Journal of Economics, 114(3): 1047-1084.

[14] Case, Anne, Darren Lubotsky, and Christina Paxson. 2002. "Economic Status and Health in Childhood: The Origins of the Gradient." American Economic Review, 92(5): 1308-1334.

[15] Case, Anne, Angela Fertig, and Christina Paxon. 2005. "The Lasting Impact of Childhood Health and Circumstance." Journal of Health Economics, 24: 365-389.

[16] Chay, Kenneth, and Michael Greenstone. 2000. "The Convergence in Black-White Infant Mortality Rates during the 1960s." American Economic Review, 90(2): 326-332.

[17] Community Agency for Social Enquiry (CASE). 1995. A National Household Survey of Health Inequalities in South Africa. Prepared for the Henry J. Kaiser Family Foundation: Johannesburg.

[18] Community Agency for Social Enquiry (CASE). 1999. The Second Kaiser Family Foundation Survey of Health Care in South Africa. Prepared for the Henry J. Kaiser Family Foundation: Johannesburg

[19] Cooper, Diane, Chelsea Morroni, Phyllis Orner, Jennifer Moodley, Jane Harries, Lee Cullingworth, and Margaret Hoffman. 2004. "Ten Years of Democracy in South Africa: Documenting Transformation in Reproductive Health Policy and Status." Reproductive Health Matters, 12(24), 70-85. 
[20] Currie, Janet. 2008. "Healthy, Wealthy, and Wise: Socioeconomic Status, Poor Health in Childhood, and Human Capital Development." National Bureau of Economic Research Working Paper 13987.

[21] Currie, Janet and Wanchuan Lin. 2007. "Chipping Away at Health: More on the Relationship between Income and Child Health." Health Affairs, 26(2): 331-344.

[22] Das, Jishnu and Jeffrey Hammer. 2007. "Money for Nothing: The Dire Straits of Medical Practice in Delhi, India." Journal of Development Economics, 83(1): 1-36.

[23] Deaton, Angus. 2006. "Global Patterns of Income and Health: Facts, Interpretations, and Policies." National Bureau of Economic Research Working Paper 12735.

[24] Deininger, Klaus and Paul Mpuga. 2004. "Economic and Welfare Effects of the Abolition of Health User Fees: Evidence from Uganda." World Bank Policy Research Working Paper 3276. The World Bank: Washington D.C.

[25] Department of Health. 1995. Maternal Child and Women's Health Draft Policy Document. Department of Health: Pretoria.

[26] Department of Health. 1998. Department of Health Achievements and Highlights of 199\%. Department of Health: Pretoria.

[27] Department of Health. 2000. Health Sector Strategic Framework 1999-2004. Department of Health: Pretoria.

[28] Dinkelman, Taryn. 2008. "The Long-term Effects of Being Born in a Drought: Evidence from the Cape Area Panel Study 2002-2006." Unpublished.

[29] Duflo, Esther. 2001. "Schooling and Labor Market Consequences of School Construction in Indonesia: Evidence from the Unusual Policy Experiment." American Economic Review, 91(4): 795-813. 
[30] Fonn, Sharon, Makosazana Xaba, Kin San Tint, Daphney Conco, Sanjani Varkey. 1998. "Reproductive Health Services in South Africa: From Phetoric to Implementation." Reproductive Health Matters, 6(11): 22-32.

[31] Gilson, Lucy, Jane Doherty, Di McIntyre, Stephen Thomas, Vishal Briljal, Chris Bowa. 1999. The Dynamics of Policy Change: Health Care Financing in South Africa, 19941999. Centre for Health Policy (University of the Witwatersrand) and the Health Economics Unit (University of Cape Town):Johannesburg.

[32] Gilson, Lucy and Di McIntyre. 2007. "Post-Apartheid Challenges: Household Access and Use of Health Care in South Africa." International Journal of Health Services, 37(4): 673-691.

[33] Glewwe, Paul and Elizabeth M. King. 2001. "The Impact of Early Childhood Nutritional Status on Cognitive Development: Does the Timing of Malnutrition Matter?" World Bank Economic Review, 15(1): 81-113.

[34] Glewwe, Paul, Hanan G. Jacoby, and Elizabeth M. King. 2001. "Early Childhood Nutrition and Academic Achievement: A Longitudinal Analysis." Journal of Public Economics, 81(3): 345-368.

[35] Holla, Alaka, and Michael Kremer. 2009. "Pricing and Access: Lessons from Randomized Evaluations in Education and Health." Center for Global Development Working Paper 158. Center for Global Development:Washington, D.C.

[36] Khan, Sultan, Benoit Lootvoet, and Shahid Vawda. 2006. "Transcending Traditional Forms of Governance: Prospects for Co-operative Governance and Service Delivery in Durban's Tribal Authority Areas." Transformation, 62: 84-117.

[37] Klasen, Stephan. 1997. "Poverty, Inequality and Deprivation in South Africa: An Analysis of the 1993 Saldru Survey." Social Indicator Research, 41: 51-94. 
[38] Klugman, Barbara, and Di McIntyre. 2000. "From Policy, Through Budgets, to Implementation: Delivering Quality Health Care Services." In The Fifth Women's Budget, ed. Budlender D, Cape Town: IDASA

[39] Leibbrandt, Murray, and Ingrid Woolard. 1999. "A Comparison of Poverty in South Africa's Nine Provinces." Development South Africa, 16(1): 37-54.

[40] Maccini, Sharon and Dean Yang. 2009. "Under the Weather: Health, Schooling, and Economic Consequences of Early-Life Rainfall." American Economic Review, 99(3): 1006-1026.

[41] Maharaj, Pranitha, and John Cleland. 2005. "Integration of Sexual and Reproductive Health Services in KwaZulu-Natal, South Africa." Health Policy and Planning, 20(5), $310-318$.

[42] May, Julian, Michael R. Carter, Lawrence Haddad, and John Maluccio. 2000. "KwaZuluNatal Income Dynamics Study (KIDS) 1993-1998: A Longitudinal Household Data Set for South Africa Policy Analysis." Development Southern Africa, 17(4), 567-581.

[43] May, Julian, Jorge Aguero, Michael R. Carter, and Ian M. Timaeus. 2007. "The KwaZulu-Natal Income Dynamics Study (KIDS) Third Wave: Methods, First Findings and an Agenda for Future Research." Development Southern Africa, 24(5), 629-648.

[44] McCoy, David. 1996. Free Health Care for Pregnant Women and Children Under Six in South Africa: An Impact Assessment. Durban: Health Systems Trust, Child Health Unit (University of Cape Town).

[45] McIntyre, Di, and Barbara Klugman. 2003. "The Human Face of Decentralization and Integration of Health Services: Experience from South Africa." Reproductive Health Matters, 11(21), 108-119. 
[46] Moultrie, Tom A. and Ian M. Timaeus. 2003. "The South African Fertility Decline: Evidence from Two Censes and a Demographic and Health Survey." Population Studies, 57(3): 265-283.

[47] Oster, Emily. 2009. "Does Increased Access Increase Equality? Gender and Child Health Investments in India." Journal of Development Economics, 89(1): 62-76.

[48] Pritchett, Lant, and Lawrence H. Summers. 1996. "Wealthier is Healthier." Journal of Human Resources, 31(4): 841-868.

[49] Republic of South Africa. 1994. White Paper on Reconstruction and Development. Government's Strategy for Fundamental Transformation. Pretoria: Government Printer. Cape Town: WPJ/1994.

[50] Schneider, Helen and Lucy Gilson. 1999. "The Impact of Free Maternal Health Care in South Africa." In Safe motherhood Initiatives: Critical Issues, ed. Marge Bere and T.K. Sundari Ravindran, 93-101. Oxford, England: Blackwell Science.

[51] WHO Multicentre Growth Reference Study Group. 2006. WHO Child Growth Standards: Length/Height-for-age, Weight-for-age, Weight-for-length, Weight-for-height and Body Mass Index-for-age: Methods and Development. Geneva: World Health Organization.

[52] Wilkinson, David, Eleanor Gouws, Marlene Sach, and Salim S. Abdool Karim. 2001. "Effect of Removing User Fees on Attendance for Curative and Preventive Primary Health Care Services in Rural South Africa." Bulletin of the World Health Organization, 79(7), 665-671.

[53] Yamauchi, Futoshi. 2008. "Early Childhood Nutrition, Schooling and Sibling Inequality in a Dynamic Context: Evidence from South Africa." Economic Development and Cultural Change, 56:657-682. 


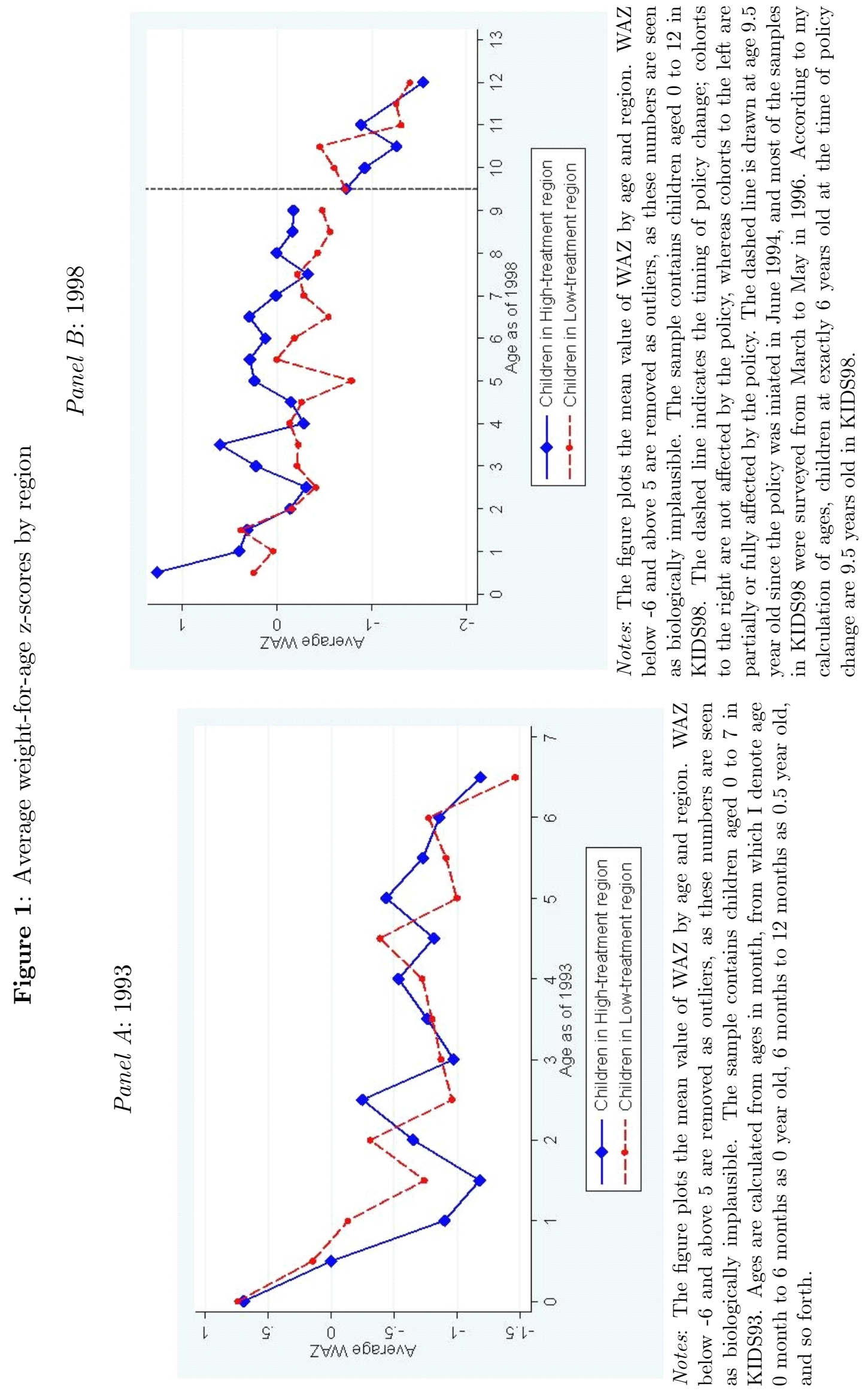


Table 1: Summary Statistics of Baseline Sample in KIDS93

\begin{tabular}{lccc}
\hline \hline Variables & High & Low & Diff. \\
\hline Panel A: Child characteristics & & & \\
Age & 3.28 & 3.39 & -0.111 \\
& {$[1.60]$} & {$[1.64]$} & $(.114)$ \\
Weight $(\mathrm{kg})$ & 13.02 & 13.04 & -0.022 \\
& {$[4.11]$} & {$[4.09]$} & $(.290)$ \\
Height (cm) & 87.6 & 88.15 & -0.551 \\
& {$[14.29]$} & {$[15.25]$} & $(1.062)$ \\
Panel B: Household characteristics & & & \\
Monthly income & 1037.36 & 1038.61 & -1.250 \\
& {$[984.66]$} & {$[1150.63]$} & $(99.25)$ \\
Father's education & 4.33 & 3.91 & 0.426 \\
& {$[3.43]$} & {$[3.24]$} & $(.448)$ \\
Mother's education & 5.34 & 4.85 & 0.494 \\
& {$[3.39]$} & {$[3.36]$} & $(.329)$ \\
Panel C: Community characteristics & & & \\
No. of communities & 26 & 28 & \\
No. of observations & 350 & 482 & \\
No. of primary schools & 2.42 & 1.39 & $1.03^{* *}$ \\
& {$[2.35]$} & {$[1.34]$} & $(.52)$ \\
No. of other types of & 0.462 & 0.036 & $0.426^{* * *}$ \\
health infrastructures & {$[.81]$} & {$[.036]$} & $(.158)$ \\
\hline \hline
\end{tabular}

Notes: The table provides summary statistics of variable means as of 1993. Panel A reports characteristics of children under age 7 whose anthropometric data are available. Panel $\mathrm{B}$ presents household characteristics of these children, and Panel $\mathrm{C}$ shows characteritics of communities these households resided. Other types of health infrastructure include public hospital, dispensaries, and maternity home. Column 1 consists of the high treatment region, where there was a clinic in 1993, whereas Column 2 contains the low treatment region, where there was no clinic. Column 3 estimates the difference in means between the two regions under the null hypothesis that there is no difference in the means. Standard deviations are in square brackets and standard errors are in parentheses.

Significant at $\mathrm{p}<0.01^{* * *}, \mathrm{p}<0.05^{* *}, \mathrm{p}<0.1^{*}$ levels. 
Table 2: Difference-in-differences matrix in means of health status by cohort and level of exposure to the policy

Panel A: Age level analysis

\begin{tabular}{llll}
\hline \hline & \multicolumn{3}{l}{ weight-for-age z-score } \\
\cline { 2 - 4 } & High & Low & Diff. \\
\hline \multirow{3}{*}{ Young Cohort: } & 0.321 & -0.069 & 0.391 \\
Aged 0 to 3 in KIDS98 & $(.106)$ & $(.079)$ & $(.130)$ \\
Observations & {$[212]$} & {$[288]$} & \\
& & & \\
Old Cohort: & -0.545 & -0.414 & -0.131 \\
Aged 0 to 3 in KIDS93 & $(.110)$ & $(.089)$ & $(.140)$ \\
Observations & {$[246]$} & {$[325]$} & \\
& & & \\
Difference & 0.867 & 0.345 & 0.522 \\
& $(.154)$ & $(.121)$ & $(.258)$ \\
\hline \hline
\end{tabular}

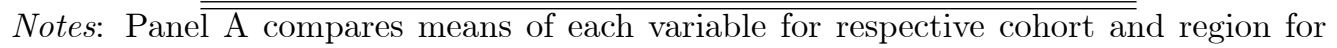
the same age group. The young cohort consists of children aged 0 to 3 in KIDS98, who are fully exposed to the policy. The old cohort consists of children aged 0 to 3 in KIDS93, who have no exposure to the policy. Standard errors are in parentheses, and number of observations in each cell is provided in square brackets. Standard errors for the difference-in-differences are clustered at the community*Cohort level.

\begin{tabular}{|c|c|c|c|}
\hline & \multicolumn{3}{|c|}{ weight-for-age z-score } \\
\hline & High & Low & Diff. \\
\hline Young Cohort: & 0.045 & -0.345 & 0.39 \\
\hline Aged 5 to 8 in KIDS98 & $(.077)$ & $(.062)$ & $(.098)$ \\
\hline Observations & {$[283]$} & {$[341]$} & \\
\hline Old Cohort: & -0.545 & -0.414 & -0.131 \\
\hline Aged 0 to 3 in KIDS93 & $(.110)$ & $(.089)$ & $(.140)$ \\
\hline Observations & {$[246]$} & {$[325]$} & \\
\hline Difference & $\begin{array}{c}0.59 \\
(.131)\end{array}$ & $\begin{array}{l}0.069 \\
(.108)\end{array}$ & $\begin{array}{l}0.521 \\
(.244)\end{array}$ \\
\hline
\end{tabular}

Notes: Panel $\overline{\bar{B} \text { compares means of each variable for the same cohort. The young cohort }}$ consists of children aged 5 to 8 in KIDS98. The old cohort consists of children aged 0 to 3 in KIDS93. Although I use the term "young cohort" and "old cohort" to be consistent throughout the paper, these are the same cohort observed across time. 


\begin{tabular}{lccc}
\multicolumn{3}{c}{ Panel $C$ : Placebo experiment in pre-treatment period } \\
\hline \hline & \multicolumn{3}{c}{ weight-for-age z-score } \\
\cline { 2 - 4 } & High & Low & Diff. \\
\hline \multirow{3}{*}{ Young Cohort: } & -0.545 & -0.414 & -0.131 \\
Aged 0 to 3 in KIDS93 & $.110)$ & $(.089)$ & $(.140)$ \\
Observations & {$[246]$} & {$[325]$} & \\
& & & \\
Old Cohort: & -0.668 & -0.754 & 0.086 \\
Aged 4 to 7 in KIDS93 & $(.140)$ & $(.120)$ & $(.185)$ \\
Observations & {$[103]$} & {$[147]$} & \\
& & & \\
Difference & 0.122 & 0.339 & -0.217 \\
& $(.192)$ & $(.155)$ & $(.272)$ \\
\hline
\end{tabular}

Notes: Panel C compares means of each variable in the placebo experiment as of 1993. The young cohort consists of children aged 0 to 3 in KIDS93, and the old cohort consists of children aged 4 to 7 in KIDS93. Both of the cohorts are not exposed to the policy.

Panel D: Placebo experiment in post-treatment period

\begin{tabular}{lccc}
\hline \hline & \multicolumn{3}{c}{ weight-for-age z-score } \\
\cline { 2 - 4 } & High & Low & Diff. \\
\hline Young Cohort: & -1.016 & -0.830 & -0.186 \\
Aged 10 to 12 in KIDS98 & $(.095)$ & $(.079)$ & $(.124)$ \\
Observations & {$[76]$} & {$[114]$} & \\
Old Cohort: & & & \\
Aged 5 to 7 in KIDS93 & -0.653 & -0.981 & 0.328 \\
Observations & {$[53)$} & $(.174)$ & $(.261)$ \\
Difference & {$[66]$} & \\
& -0.362 & 0.151 & -0.514 \\
& $(.197)$ & $(.168)$ & $(.298)$ \\
\hline \hline
\end{tabular}

Notes: Panel D compares means of each variable in the placebo experiment across time. The young cohort consists of children aged 10 to 12 in KIDS98, and the old cohort consists of children aged 5 to 7 in KIDS93. Samples are not entirely the same individuals due to minor differences in the timing of data collection, which slightly changed individuals contained in each cohort since it is sorted by age in years at the time of data collection. However, it intends to trace the same cohort who has no exposure to the policy. Age 7 years old as of 1993, and thus age 12 years old as of 1998 , is the oldest children whose anthropometric data are available. 
Table 3: Determinants of health status in age level analysis

\begin{tabular}{|c|c|c|c|c|c|}
\hline \multirow[b]{2}{*}{ Variables } & \multicolumn{5}{|c|}{ Dependent Variable } \\
\hline & (1) & (2) & $(3)$ & $(4)$ & $(5)$ \\
\hline High*Young & $\begin{array}{c}0.522^{* *} \\
(.258)\end{array}$ & $\begin{array}{c}0.571^{* * *} \\
(.186)\end{array}$ & $\begin{array}{c}0.515^{* * *} \\
(.179)\end{array}$ & $\begin{array}{c}0.692^{* * *} \\
(.212)\end{array}$ & $\begin{array}{c}0.638^{* * *} \\
(.203)\end{array}$ \\
\hline Young cohort & $\begin{array}{c}0.345^{* *} \\
(.136)\end{array}$ & & & & \\
\hline High-treatment regions & $\begin{array}{l}-0.131 \\
(.196)\end{array}$ & & & & \\
\hline Household characteristics & & & & & \\
\hline Father's education & & & $\begin{array}{l}0.015 \\
(.018)\end{array}$ & & $\begin{array}{l}0.016 \\
(.017)\end{array}$ \\
\hline Mother's education & & & $\begin{array}{l}-0.014 \\
(.016)\end{array}$ & & $\begin{array}{r}-0.014 \\
(.016)\end{array}$ \\
\hline Household size & & & $\begin{array}{l}-0.014 \\
(.010)\end{array}$ & & $\begin{array}{r}-0.014 \\
(.011)\end{array}$ \\
\hline Log monthly income & & & $\begin{array}{c}0.154^{* * * *} \\
(.055)\end{array}$ & & $\begin{array}{c}0.155^{* * *} \\
(.054)\end{array}$ \\
\hline Community characteristics & & & & & \\
\hline $\begin{array}{l}\text { Immunization campaign } \\
\text { since } 1993\end{array}$ & & & & $\begin{array}{c}0.902^{* * *} \\
(.225)\end{array}$ & $\begin{array}{c}0.925^{* * *} \\
(.224)\end{array}$ \\
\hline $\begin{array}{l}\text { No. of other health } \\
\text { centers in } 1993\end{array}$ & & & & $\begin{array}{c}-0.321^{* *} \\
(.136)\end{array}$ & $\begin{array}{c}-0.330^{* *} \\
(.136)\end{array}$ \\
\hline Constant & $\begin{array}{c}-0.414^{* * *} \\
(.115)\end{array}$ & $\begin{array}{c}-2.313^{* * *} \\
(.674)\end{array}$ & $\begin{array}{c}-3.31^{* * *} \\
(.792)\end{array}$ & $\begin{array}{c}-3.217^{* * *} \\
(.736)\end{array}$ & $\begin{array}{c}-4.298^{* * *} \\
(.848)\end{array}$ \\
\hline Cohort FE & No & Yes & Yes & Yes & Yes \\
\hline Community FE & No & Yes & Yes & Yes & Yes \\
\hline Observations & 1071 & 1071 & 1071 & 1071 & 1071 \\
\hline$R^{2}$ & 0.04 & 0.2 & 0.21 & 0.20 & 0.21 \\
\hline
\end{tabular}

Notes: The table presents estimates of the effect of gaining access to health infrastructure on health status among children aged 0 to 3 in KIDS98. The sample corresponds to Panel A of Table 2. The dependent variable is health status, measured by WAZ. WAZ below -6 and above 5 are removed as outliers, as these numbers are seen as biologically implausible. Observations are at the individual level. Robust standard errors are clustered at the community*Cohort level. Column 1 provides estimates of equation 1 which simply controls for young and high dummy variables, whereas other columns provide estimates of equation 2 , which includes each cohort and community fixed effects.

Significant at $\mathrm{p}<0.01^{* * *}, \mathrm{p}<0.05^{* *}, \mathrm{p}<0.1^{*}$ levels. 


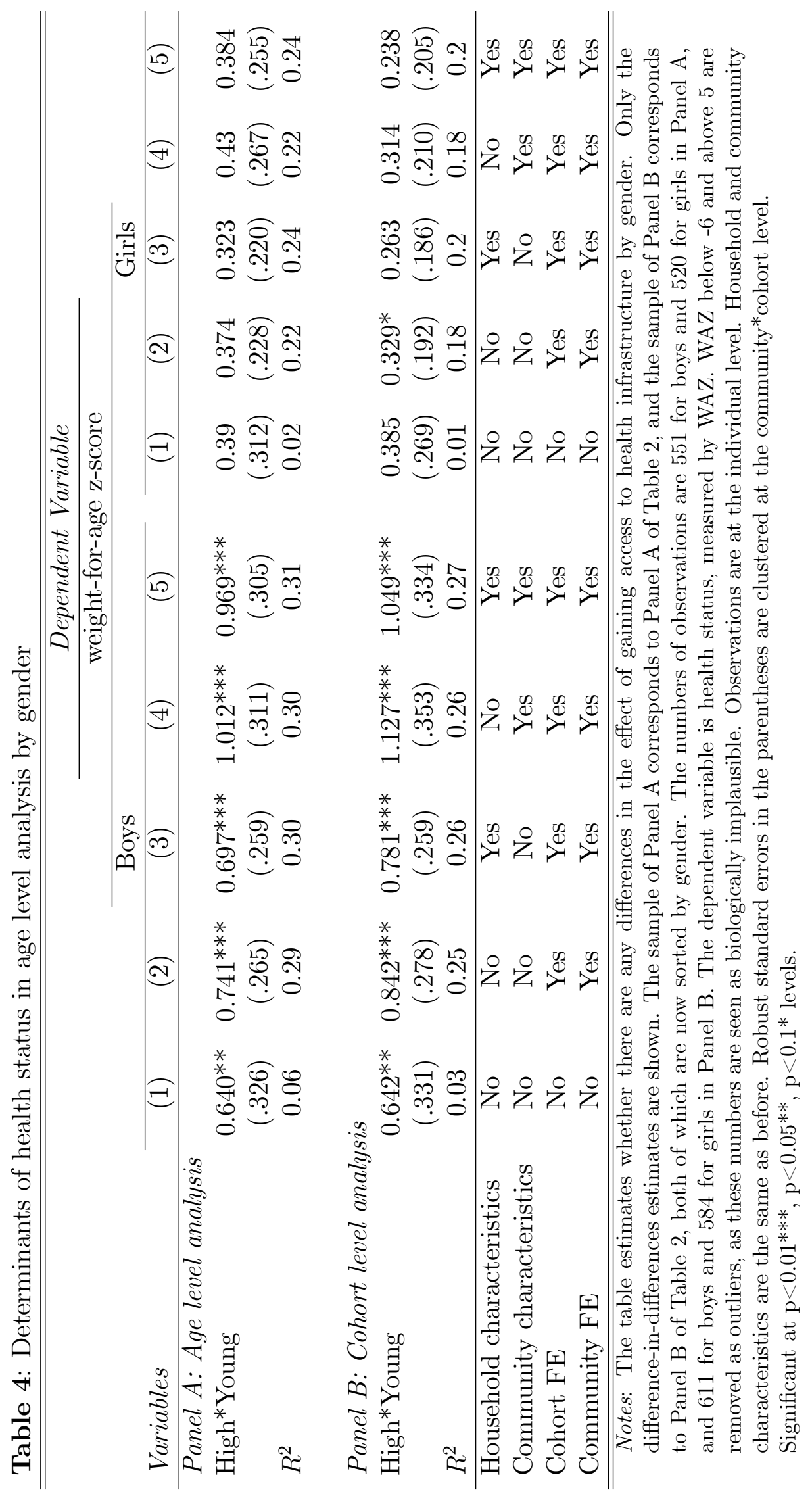


Table 5: Determinants of health status in cohort level analysis

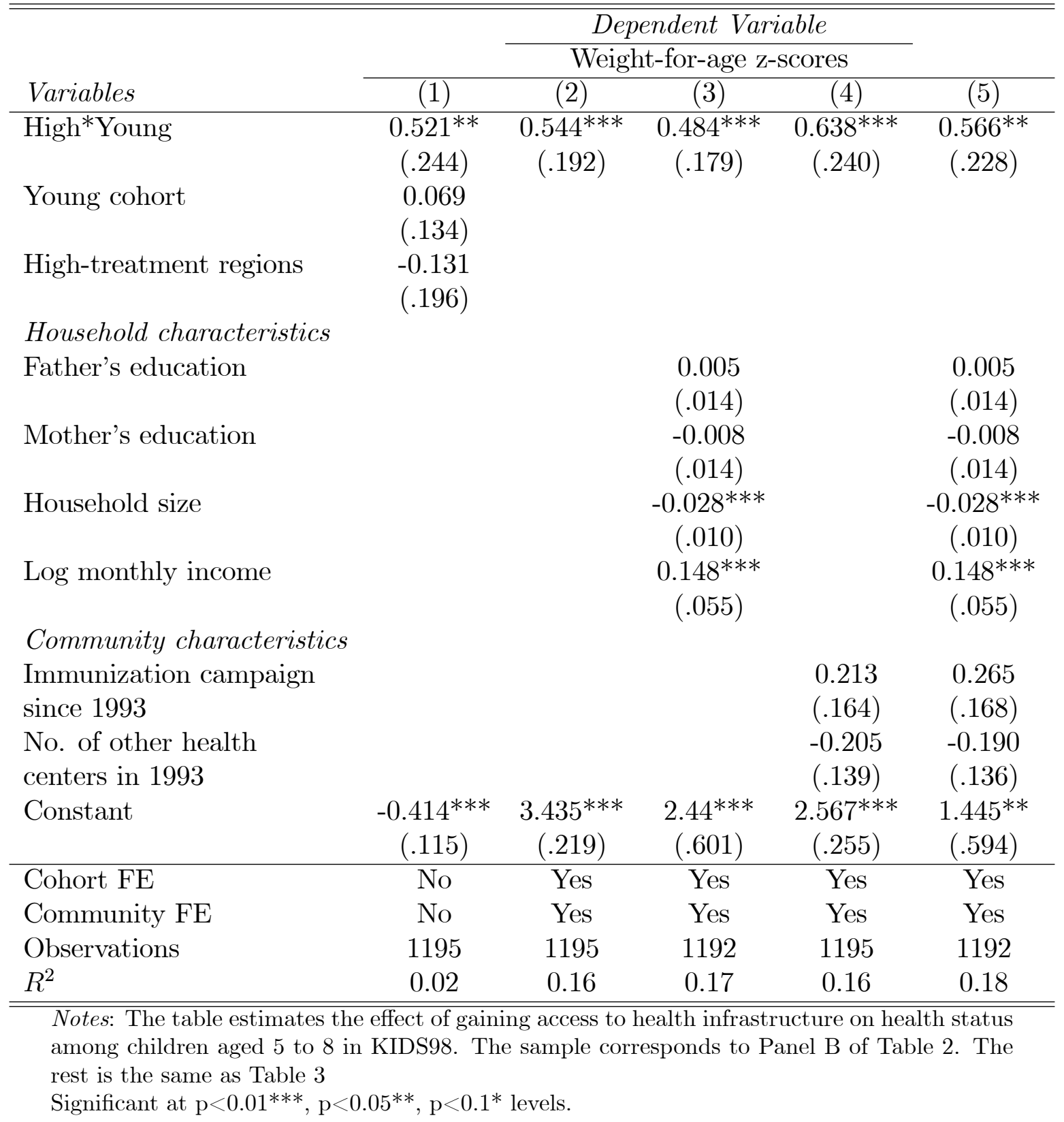


Table 6: Determinants of clinical availability

\begin{tabular}{lc}
\hline \hline Independent variable & \\
\hline Mean total household income & 0.049 \\
(thousands) & $(.092)$ \\
Mean household size & -0.069 \\
& $(.044)$ \\
Mean years of paternal education & 0.005 \\
& $(.052)$ \\
Mean years of maternal education & -0.021 \\
& $(.061)$ \\
$R^{2}$ & 0.11 \\
\hline \hline
\end{tabular}

Notes: This table provides estimates of whether there is evidence that initial availability of clinics as of 1993 is based on any household characteristics. Observations are at the household levels, from which each variable mean is calculated at the community level. Robust standard errors are in parentheses, clustering at the community level. The regression includes indicators for metro/urban/rural area. The dependent variable is a dummy taking a value of 1 if a community is in the high treatment region, and 0 otherwise. 
Table 7: Placebo Experiment

\begin{tabular}{lccccc}
\hline \hline & \multicolumn{5}{c}{ Dependent Variable } \\
\cline { 2 - 5 } Variables & $(1)$ & $(2)$ & $(3)$ & $(4)$ & $(5)$ \\
\hline Panel C: Pre-treatment period & & & & & \\
High*Young & -0.217 & -0.145 & -0.157 & -0.145 & -0.157 \\
\multicolumn{1}{c}{} & $(.272)$ & $(.188)$ & $(.190)$ & $(.188)$ & $(.190)$ \\
$R^{2}$ & 0.01 & 0.19 & 0.20 & 0.19 & 0.20 \\
Panel D: Post-treatment period & & & & & \\
High*Young & $-0.513^{*}$ & -0.444 & $-0.479^{*}$ & -0.479 & -0.506 \\
& $(.298)$ & $(.273)$ & $(.274)$ & $(.315)$ & $(.316)$ \\
$R^{2}$ & 0.01 & 0.23 & 0.24 & 0.23 & 0.24 \\
\hline Household characteristics & No & No & Yes & No & Yes \\
Community characteristics & No & No & No & Yes & Yes \\
Cohort FE & No & Yes & Yes & Yes & Yes \\
Community FE & No & Yes & Yes & Yes & Yes \\
\hline \hline
\end{tabular}

Notes: Panel $\mathrm{C}$ tests whether there is evidence that children in each region show any differential trends in health development. The sample corresponds to Panel $\mathrm{C}$ of Table 2. Panel D estimates whether the availability of clinics in the community as of 1993 had any impacts on cohorts who were not exposed to the policy. The sample corresponds to Panel D in Table 2. The rest is the same as Table 3.

Significant at $\mathrm{p}<0.01^{* * *}, \mathrm{p}<0.05^{* *}, \mathrm{p}<0.1^{*}$ levels.

Table 8: Construction of new clinics

\begin{tabular}{lc}
\hline \hline Independent variable & \\
\hline High & $-0.879^{* * *}$ \\
& $(.220)$ \\
Constant & $1.071^{* * *}$ \\
& $(.153)$ \\
Observations & 54 \\
$R^{2}$ & 0.24 \\
\hline \hline
\end{tabular}

Notes: The table tests whether there is evidence that clinical constructions conducted after 1994 are based on the initial availability of clinics as of 1993. The dependent variable is the number of clinics built between 1993 and 1998, and the observation is at the community level. High refers to the high treatment region.

Significant at $\mathrm{p}<0.01^{* * *}$. 


\section{Appendix}

Figure A1: Average weight-for-age z-scores by gender in 1993

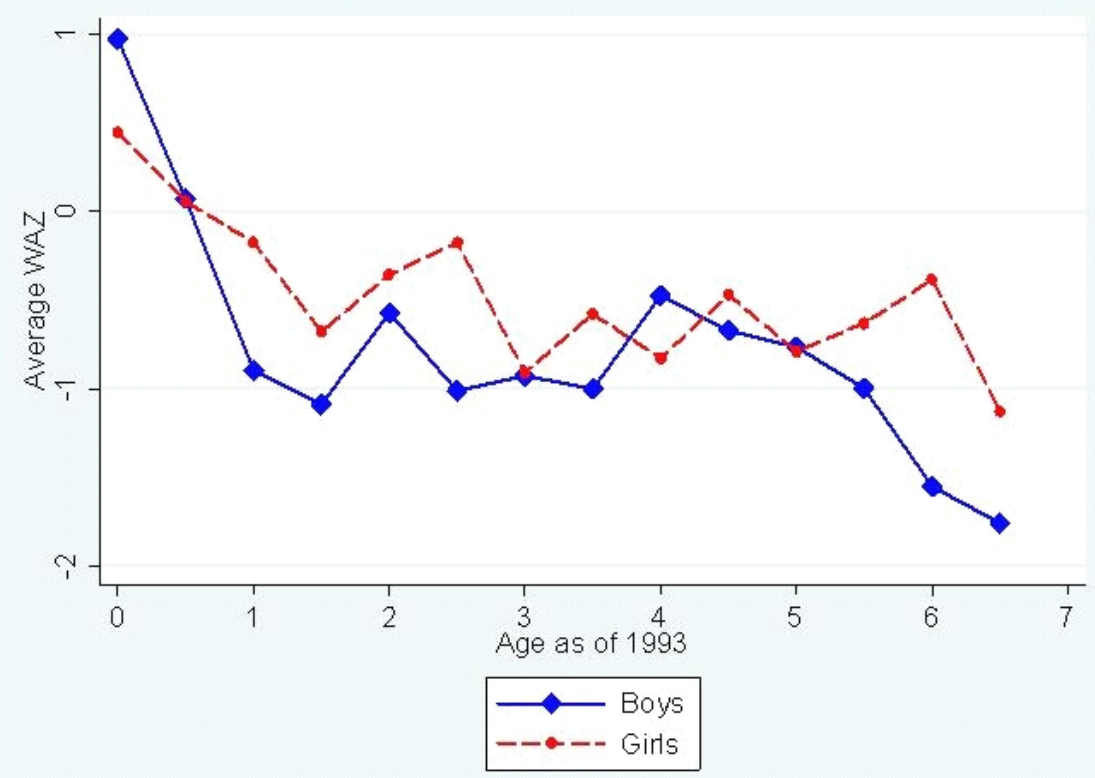

Notes: The figure plots the mean value of WAZ by age and gender. The rests are the same as Figure 1 Panel A. 
Table A1: Removing migrants from the main analyses Panel A: Age level analysis

\begin{tabular}{|c|c|c|c|}
\hline & \multicolumn{3}{|c|}{ Weight-for-age z-scores } \\
\hline & High & Low & Diff. \\
\hline Young Cohort: & 0.346 & -0.055 & 0.401 \\
\hline Aged 0 to 3 in KIDS98 & $(.110)$ & $(.080)$ & $(.133)$ \\
\hline Observations & {$[204]$} & {$[282]$} & \\
\hline Old Cohort: & -0.545 & -0.414 & -0.131 \\
\hline Aged 0 to 3 in KIDS93 & $(.110)$ & $(.089)$ & $(.140)$ \\
\hline Observations & {$[246]$} & {$[325]$} & \\
\hline Difference & 0.891 & 0.359 & 0.532 \\
\hline & $(.157)$ & $(.121)$ & $(.261)$ \\
\hline \multicolumn{4}{|c|}{$\begin{array}{l}\text { Notes: The observation in } 1998 \text { are restricted to the } \\
\text { households who resided in the same communities as in } \\
\text { 1993. The rests are the same as Table } 2 \text {. }\end{array}$} \\
\hline \multicolumn{4}{|c|}{ Panel B: Cohort level analysis } \\
\hline & \multicolumn{3}{|c|}{ Weight-for-age z-scores } \\
\hline & High & Low & Diff. \\
\hline Young Cohort: & 0.068 & -0.348 & 0.416 \\
\hline Aged 5 to 8 in KIDS98 & $(.077)$ & $(.063)$ & $(.099)$ \\
\hline Observations & {$[277]$} & {$[331]$} & \\
\hline Old Cohort: & -0.545 & -0.414 & -0.131 \\
\hline Aged 0 to 3 in KIDS93 & $(.110)$ & $(.089)$ & $(.140)$ \\
\hline Observations & {$[246]$} & {$[325]$} & \\
\hline Difference & $\begin{array}{l}0.613 \\
(.132) \\
\end{array}$ & $\begin{array}{l}0.066 \\
(.111) \\
\end{array}$ & $\begin{array}{l}0.547 \\
(.243) \\
\end{array}$ \\
\hline
\end{tabular}

Notes: Same as Panel A. 
Table A2: Cohort-by-cohort effects of clinics on health status

\begin{tabular}{|c|c|c|c|c|}
\hline \multirow[b]{3}{*}{ Age in 1998} & \multicolumn{3}{|c|}{$\begin{array}{l}\text { Dependent variable } \\
\text { weight-for-age z-score }\end{array}$} & \\
\hline & \multirow[b]{2}{*}{ Yrs of exp. } & \multicolumn{3}{|c|}{ Specification 1} \\
\hline & & (1) & (2) & (3) \\
\hline 0 & 1 & $\begin{array}{c}1.187^{* * *} \\
(.449)\end{array}$ & $\begin{array}{c}1.140^{* *} \\
(.539)\end{array}$ & $\begin{array}{c}1.862^{* * *} \\
(.604)\end{array}$ \\
\hline 1 & 2 & $\begin{array}{l}0.388 \\
(.289)\end{array}$ & $\begin{array}{c}0.774^{*} \\
(.409)\end{array}$ & $\begin{array}{l}0.137 \\
(.421)\end{array}$ \\
\hline 2 & 3 & $\begin{array}{l}0.235 \\
(.298)\end{array}$ & $\begin{array}{c}0.909^{*} \\
(.468)\end{array}$ & $\begin{array}{l}-0.384 \\
(.292)\end{array}$ \\
\hline 3 & 4 & $\begin{array}{c}0.773^{* * *} \\
(.265)\end{array}$ & $\begin{array}{c}1.225^{* * * *} \\
(.379)\end{array}$ & $\begin{array}{l}0.347 \\
(.301)\end{array}$ \\
\hline 4 & 5 & $\begin{array}{l}0.235 \\
(.303)\end{array}$ & $\begin{array}{c}0.657^{*} \\
(.386)\end{array}$ & $\begin{array}{l}-0.175 \\
(.384)\end{array}$ \\
\hline 5 & 5 & $\begin{array}{c}0.705^{* *} \\
(.328)\end{array}$ & $\begin{array}{c}0.936^{* *} \\
(.458)\end{array}$ & $\begin{array}{l}0.471 \\
(.395)\end{array}$ \\
\hline 6 & 4 & $\begin{array}{c}0.670^{* *} \\
(.284)\end{array}$ & $\begin{array}{c}1.444^{* * *} \\
(.396)\end{array}$ & $\begin{array}{r}-0.129 \\
(.398)\end{array}$ \\
\hline 7 & 3 & $\begin{array}{l}0.269 \\
(.257)\end{array}$ & $\begin{array}{c}0.51 \\
(.401)\end{array}$ & $\begin{array}{l}0.071 \\
(.300)\end{array}$ \\
\hline 8 & 2 & $\begin{array}{l}0.418 \\
(.266)\end{array}$ & $\begin{array}{c}0.883^{* *} \\
(.419)\end{array}$ & $\begin{array}{l}-0.022 \\
(.290)\end{array}$ \\
\hline 9 & 1 & $\begin{array}{l}0.181 \\
(.243)\end{array}$ & $\begin{array}{l}0.361 \\
(.340)\end{array}$ & $\begin{array}{c}0.12 \\
(.253)\end{array}$ \\
\hline 10 & 0 & $\begin{array}{c}-0.290 \\
(.233)\end{array}$ & $\begin{array}{l}-0.070 \\
(.334)\end{array}$ & $\begin{array}{c}-0.505^{*} \\
(.268)\end{array}$ \\
\hline Samples: & & & & \\
\hline Boys & & Yes & Yes & No \\
\hline Girls & & Yes & No & Yes \\
\hline$R^{2}$ & & 0.14 & 0.17 & 0.18 \\
\hline Observations & & 2345 & 1191 & 1154 \\
\hline
\end{tabular}

Notes: The table reports different magnitudes of effects across each age. The estimates are based on regression of $W_{i h c l}=\alpha_{0}+\alpha_{i l} \sum_{l} H_{i g h} * \lambda_{i l}+X_{h}^{\prime} \alpha_{1}+$ $\left(X_{c}^{\prime} *\right.$ Young $\left._{l}\right) \alpha_{2}+\eta_{c}+\phi_{l}+\varepsilon_{i h c l}$, where $\lambda_{i l}=1$ if individual $i$ is at age $l$.

Robust standard errors in the parentheses are clustered at the community* cohort level. 